The report highlighted in this brochure summarizes the science of climate change and the impacts of climate change on the United States, now and in the future. It focuses on climate change impacts on U.S. regions and various aspects of society and the economy such as energy, water, agriculture, and health. It is an authoritative scientific report written in plain language, with the goal of better informing public and private decision making at all levels.

The full report, along with highlights and other information can be found at: www.globalchange.gov/usimpacts

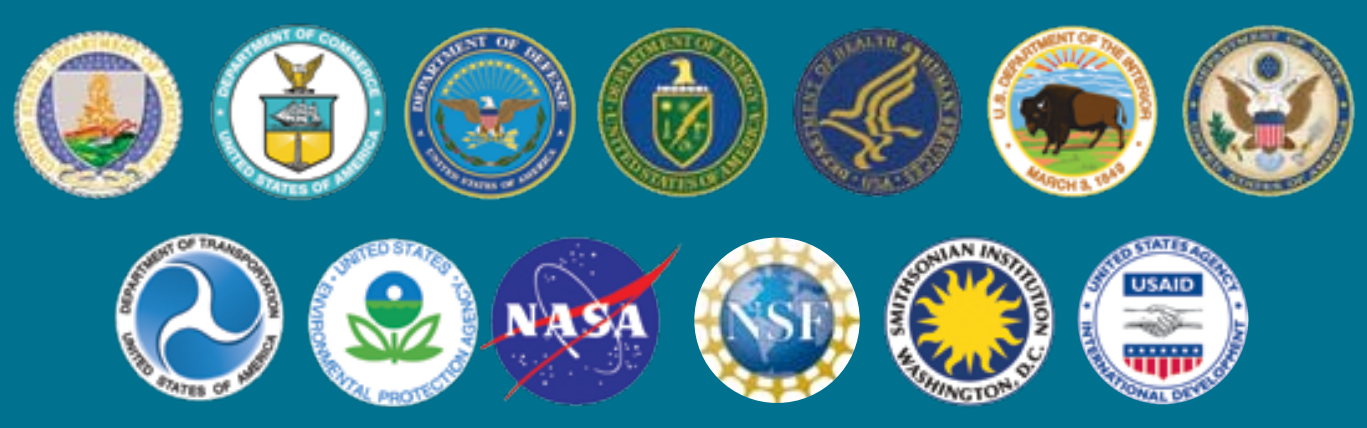

U.S. Global Change Research Program

1717 Pennsylvania Avenue, NW • Suite 250 • Washington, DC 20006 USA I-202-223-6262 (voice) • I-202-223-3065 (fax) http://www.globalchange.gov

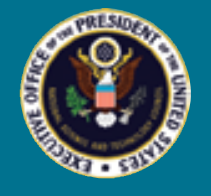

\section{Global Climate Change Impacts in the United States}

U.S. Global Change Research Program
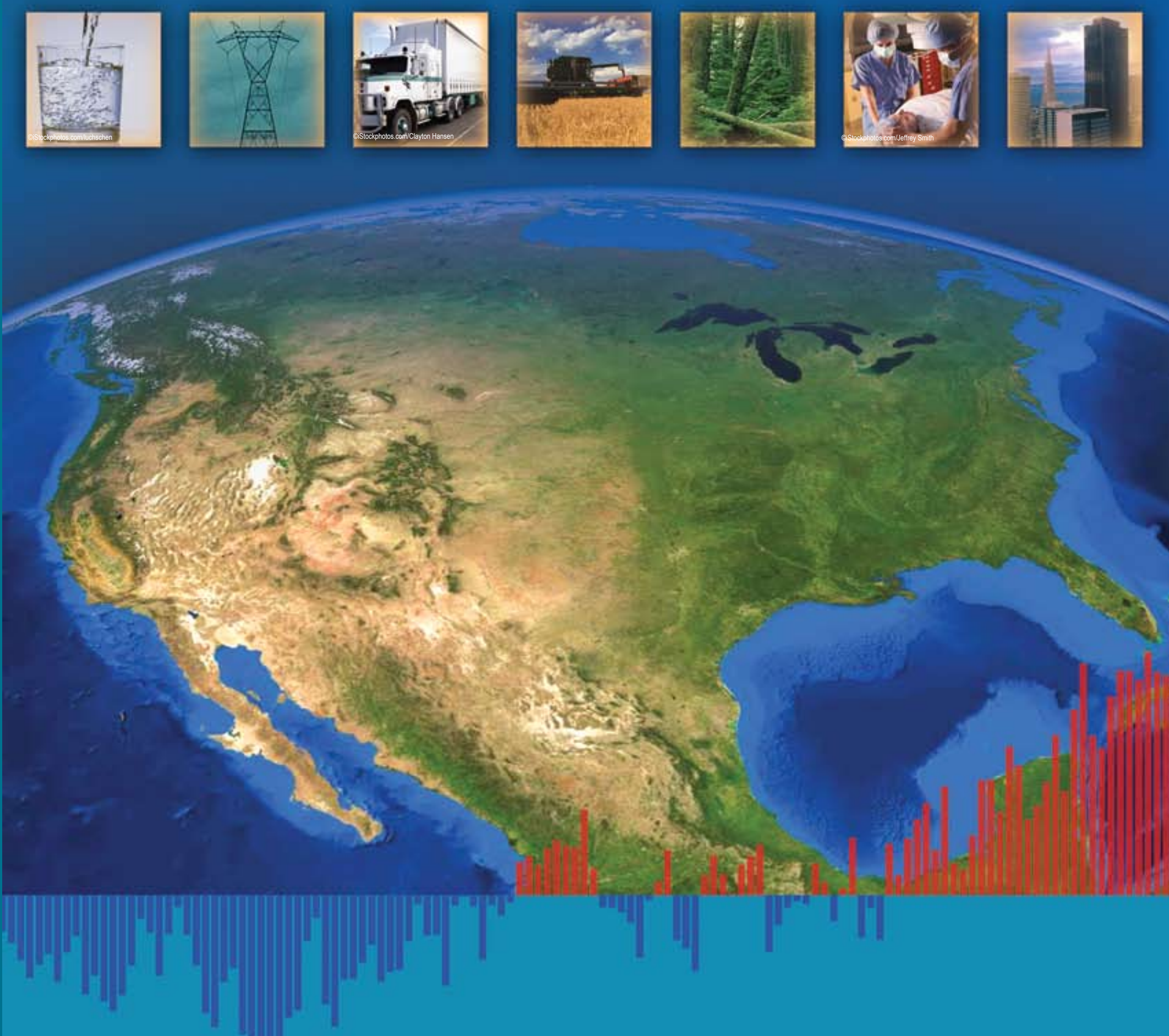


\section{Impacts of Climate Change}

Climate change is apparent now across our nation. Trends observed in recent decades include rising temperatures, increasing heavy downpours, rising sea level, longer growing seasons, reductions in snow and ice, and changes in the amounts and timing of river flows. These trends are projected to continue, with larger changes resulting from higher amounts of heat-trapping gas emissions, and smaller changes from lower amounts of these emissions. The observed changes in climate are already causing a wide range of impacts, and these impacts are expected to grow. Select examples follow.
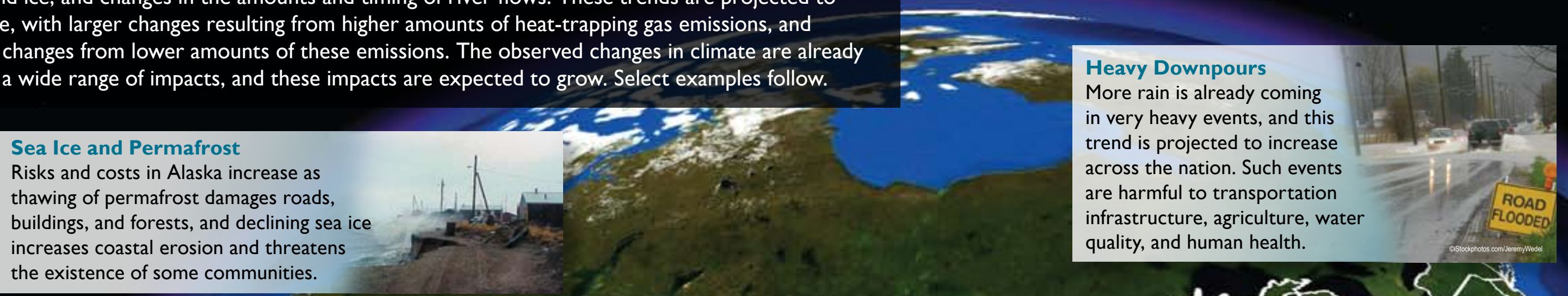

\section{$\therefore=$ rede}

the existence of some communities.

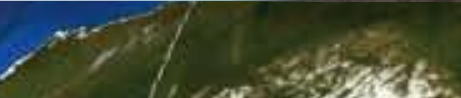

Forests
Forest growth is generally projected to

Forest growth is generally projected to
increase in much of the East, but decrease

in much of the West as water becomes even

scarcer. Major shifts in species are expected,

such as maple-beech-birch forests being
replaced by oak-hickory in the Northeast.

6. replaced by oak-hickory in the Northeast.

Insect infestations and wildfires are proj
to increase as warming progresses.

Coldwater Fish

Salmon, trout, and other

coldwater fish will face

additional stresses as water

temperatures rise and

summer streamflows decline.

Ecosystems and the tourism

and recreation they support

will be adversely affected.

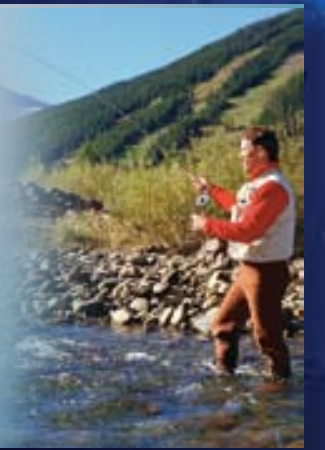

Coral Reefs

Rising water temperatures and

ocean acidification threaten coral

reefs and the rich ecosystems they

support. These and other climate-

related impacts on coastal and

marine ecosystems will have major
implications for tourism and fisheries.

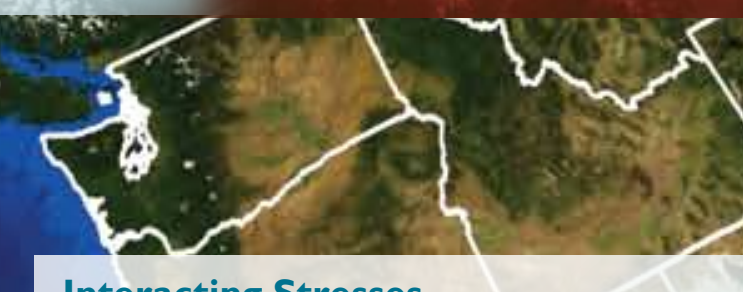

Interacting Stresses

Population shifts and development choices are making more Americans vulnerable to the impacts of climate change. An aging populace and continued population shifts to populace and continued population shifts to the Southeast, Southwest, and coastal citie amplify risks associated with extreme heat,
sea-level rise, storm surge, and increasing sea-level rise, storm surge, and
water scarcity in some regions.

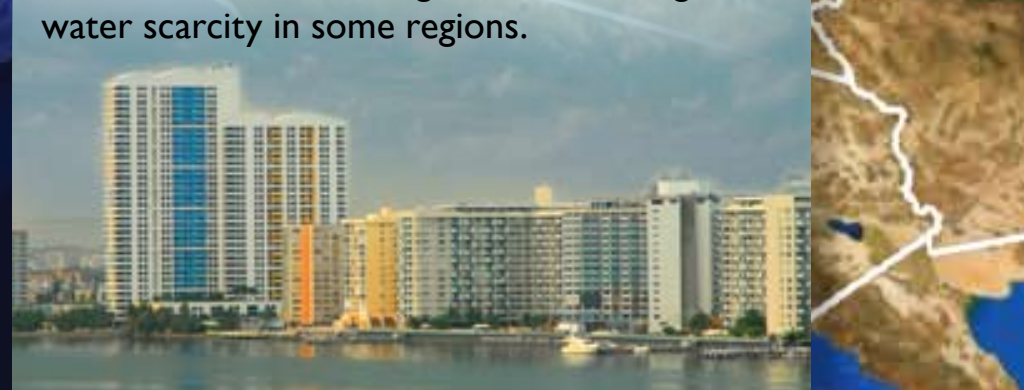

Coastal Communities

Sea-level rise and storm surge

and infrastructure inclucing

whiling

and communication systems.

Many barrier islands and coasta

marshes that protect the

coastline and support healthy

ecosystems will be los 